\title{
Catheter ablation of cardiac arrhythmias in pregnancy without fluoroscopy: A case control retrospective study
}

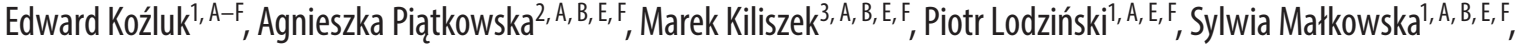 \\ Paweł Balsam ${ }^{1, A, B, E, F}$, Dariusz Rodkiewicz ${ }^{1, A, B, E, F}$, Radosław Piątkowski ${ }^{1, A, B, E, F}$, Dorota Zyśko ${ }^{2, A-F}$, Grzegorz Opolski ${ }^{1, A, B, E, F}$ \\ ${ }^{1} 1^{\text {st }}$ Chair and Department of Cardiology, Medical University of Warsaw, Poland \\ ${ }^{2}$ Chair of Emergency Medicine, Wroclaw Medical University, Poland \\ ${ }^{3}$ Department of Cardiology and Internal Diseases, Military Institute of Medicine, Warszawa, Poland \\ A - research concept and design; $\mathrm{B}$ - collection and/or assembly of data; $\mathrm{C}$ - data analysis and interpretation; \\ $D$ - writing the article; $E$ - critical revision of the article; $F$ - final approval of article
}

\section{Address for correspondence}

Dorota Zyśko

E-mail: dzysko@wp.pl

\section{Funding sources}

none declared

\section{Conflict of interest}

none declared

Received on April 3, 2016

Revised on July 11, 2016

Accepted on January 1, 2017

\begin{abstract}
Background. Cardiac arrhythmias are common in pregnant women. In most cases, they do not require treatment other than rest, electrolyte supplementation and avoidance of strong coffee and tea. Persistent arrhythmia or the ventricular rate running at a high frequency may cause hemodynamic deterioration in the fetus or in both the fetus and the mother.
\end{abstract}

Objectives. The aim of this study was to assess the prevalence and characteristics of arrhythmias in pregnant women who qualified for ablation as well as the feasibility and specific features of these interventions.

Material and methods. The study group consisted of 11 pregnant women $(16-32 \mathrm{Hbd})$ aged $31+6$. The control group consisted of 111 women aged 15-50 years (34 + 10), scheduled for ablation in 2012. The medical records of the selected study and control groups were analyzed and the following data was retrieved: age, the reason the ablation procedure was performed, the ablation duration, the number of radiofrequency applications, the total duration of radiofrequency applications, gravity, and comorbidities.

Results. In the study group, accessory pathway related arrhythmias or atrial tachycardia (AT) accounted for $62 \%$ of cases, whereas in the control group for $32 \%(p=0.042)$. All the procedures in the study group were performed with an electroanatomical system without fluoroscopy. All of the patients, but one, had no recurrence of arrhythmia. There were no complications and no overt effects were noted in the fetus.

Conclusions. Ablation of arrhythmias during pregnancy is rare. An experienced surgeon using electroanatomical system is usually able to ablate arrhythmic substrate without the use of X-ray fluoroscopy. The most prevalent causes of arhythmias in pregnant women requiring ablation are accessory pathway and AT focus.

Key words: safety, ablation, cardiac arrhythmias

DOI

$10.17219 /$ acem/68275

Copyright

Copyright by Author(s)

This is an article distributed under the terms of the

Creative Commons Attribution Non-Commercial License

(http://creativecommons.org/licenses/by-nc-nd/4.0/) 


\section{Introduction}

Cardiac arrhythmias are common in pregnant women. ${ }^{1,2}$ In most cases, they do not require treatment other than rest, electrolyte supplementation and avoidance of strong coffee and tea. Persistent arrhythmia or rapid ventricular rate response may cause hemodynamic deterioration in the fetus or in both the fetus and the mother. ${ }^{1,3}$ Therefore, these arrhythmias should be treated early and effectively. In cases of arrhythmia with severe hemodynamic compromise resistant to medical therapy and recurring after direct current cardioversion, ablation may be the treatment of choice. ${ }^{1}$ The risk tied to the ablation procedure in pregnant women is related to the use of X-rays, anesthetic agents, thromboembolic complications and the difficulty of obtaining vascular access. $^{1,4}$

The aim of this study was to assess the prevalence and characteristics of arrhythmias in pregnant women qualified for ablation and the feasibility of these operations without the use of X-rays, as well as to present the specific features of these interventions.

\section{Material and methods}

The study was designed as a retrospective case control study. A database of medical records of 5,059 patients with arrhythmia treated with catheter ablation from January 2003 to February 2014 was analyzed. The study group consisted of 11 pregnant women (16-32 hbd) aged $31 \pm 6$.

The control group consisted of 111 women aged 1550 years $(34 \pm 10)$, scheduled for ablation in 2012. In 2012, a total of 690 ablation procedures were performed.

The medical records of the selected study and control groups were retrieved and following data were analyzed: age, the reason for the ablation procedure, the ablation duration, the number of radiofrequency applications, the total duration of radiofrequency applications, comorbidities and whether a woman is currently pregnant.

In pregnant women, data regarding parity, gestational age at the time of ablation procedure, previous treatment of arrhythmia, and the history of arrhythmias during previous pregnancies was also analyzed.

\section{Ablation procedure}

All of the pregnant women gave their permission for ablation and accepted the possibility of using X-ray if necessary. During all of the procedures we tried to reduce fluoroscopy as much as possible. The study protocol was approved by the Bioethics Committee of the Wroclaw Medical University.

\section{Statistical analysis}

The continuous variables were presented as mean and standard deviations or median and interquartile range and compared with Student t-test or Mann Whitney $\mathrm{U}$ test. The discrete variables were presented as numbers and percentages and compared with $\chi^{2}$ test. P values less than 0.05 were considered statistically significant.

\section{Results}

\section{Demographics}

Pregnant women who underwent ablation accounted for $0.2 \%$ of the population treated with this method in the analyzed period. Ablations in women of reproductive age constituted $15.5 \%$ of procedures; ablations in pregnant women were $1.4 \%$ of the procedures performed in women in reproductive age.

\section{Medical history}

Table 1 presents data on the medical history of the study group. The mean age of women in the study group was slightly, but insignificantly, lower than those in the control group (30.8 \pm 5.6 vs. $34.3 \pm 10.0$ years, $\mathrm{p}=0.3)$. However, the percentage of women under 40 in the study group was significantly higher than in the control group (100 vs. $62.2 \% \mathrm{p}<0.05$ ).

In pregnant women the arrhythmia was most commonly present before pregnancy but worsened during pregnancy.

\section{Arrhythmia characteristics}

In Table 2 characteristics of arrhythmias and comorbidities in the study and control group are presented. Before the ablation in pregnant women, 2 (18.2\%) had electrical cardioversion and one was treated with amiodarone.

Table 1. Medical history of the studied group

\begin{tabular}{|lc|}
\hline Number (n) & 11 \\
Age (years) mean (SD) & $30.2 \pm 5.7$ \\
Time from arrhythmia onset (years) median (IQR) & $5.0(3.0-14.0)$ \\
Parity & \\
$\quad$ first pregnancy $n(\%)$ & $6(54.6)$ \\
$\quad$ second pregnancy $n(\%)$ & $1(9.1)$ \\
$\quad$ third pregnancy $n(\%)$ & $2(18.2)$ \\
fourth pregnancy $n(\%)$ & $2(18.2)$ \\
Past history of arrhythmias during pregnancy & \\
$\quad$ arrhythmia was not a problem & $4(36.4)$ \\
arrhythmia was a problem & $1(9.1)$ \\
Ejection fraction < 55\% n (\%) & $3(27.3)$ \\
\hline
\end{tabular}


Table 2. Characteristics of arrhythmias and comorbidities in the study and control group

\begin{tabular}{|c|c|c|c|}
\hline & $\begin{array}{l}\text { Study group } \\
\qquad n=11\end{array}$ & $\begin{array}{l}\text { Control group } \\
\qquad n=111\end{array}$ & $\mathrm{p}$ \\
\hline $\begin{array}{l}\text { WPW, n (\%) } \\
\text { AVNRT, n (\%) } \\
\text { PJRT } \\
\text { Atrial tachycardia, n (\%) } \\
\text { VES, n (\%) } \\
\text { Atrial fibrillation/atrial flutter, n (\%) }\end{array}$ & $\begin{array}{l}3(27.3) \\
2(18.2) \\
1(9.1) \\
3(27.3) \\
2(18.2) \\
0(0) \\
0(0)\end{array}$ & $\begin{array}{c}18(16.4) \\
41(36.9) \\
0(0) \\
18(16.4) \\
16(14.4) \\
12(10.8) \\
6(5.4)\end{array}$ & ns. \\
\hline Congenital heart disease, n (\%) & $0(0)$ & $2(1.8)$ & ns. \\
\hline Inherited electrical disturbances, n (\%) & $0(0)$ & $1(1.8)$ & ns. \\
\hline Women with comorbidities, n (\%) & $2(18.2)$ & $22(20.0)$ & ns. \\
\hline
\end{tabular}

\section{Ablation procedures}

All of the procedures in pregnant women have been performed using solely electronaatomical systems (CARTO -9 , EnSite - 1) with no fluoroscopy use. Nine women underwent RF ablation and one woman underwent cryoablation. Figs. 1 and 2 contain representative CARTO and EnSite mappings.

\section{Vascular access}

In pregnant women catheters were introduced to the right heart by the right internal jugular vein ( 1 or 2 introducers). In one patient, femoral transaortic approach was used for the left side accessory pathway ablation. Difficulty in obtaining vascular access occurred in 1 patient who withdrew her consent to perform the procedure after the anesthesiologist was unable to catheter her internal jugular vein. A ultrasonography revealed a vascular anomaly.
In the control group all procedures were performed using the femoral approach, and the electroanatomical system was used in 61 patients (55\%). In this group fluoroscopyfree ablation was performed in 23 patients (20.7\%).

\section{Second stage ablation in study group}

In two cases in the study group, the ablation procedure was planned for two sessions: the first session to provided symptoms control and the second session, carried out after birth, to eliminate arrhythmia substrate. In one of these cases first session proved to be sufficient for ending arrhythmia and the second session was unnecessary.

\section{Pregnancy outcome}

The procedures were not associated with any complications. All women ablated during the pregnancy gave birth to healthy full-term children.

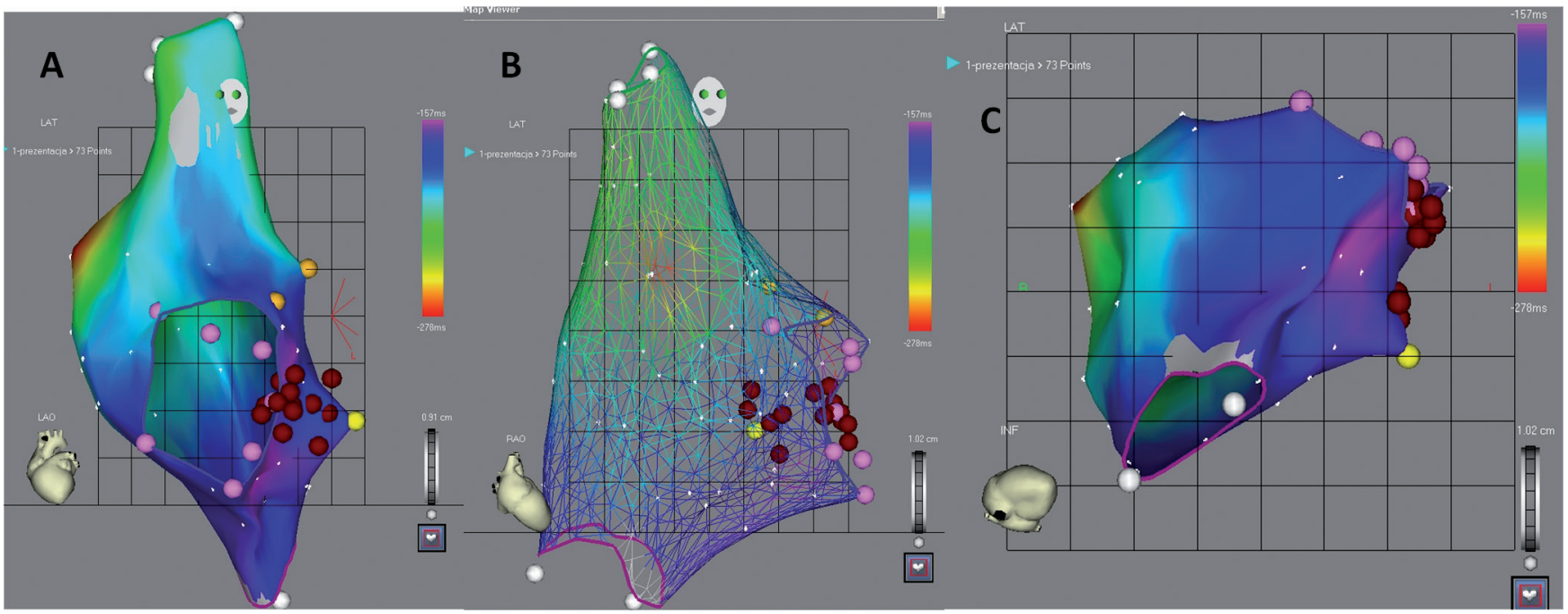

Fig. 1. Carto map performed during sinus rhythm in a woman at 24 weeks of gestation, who had slow atrioventricular pathway ablation. Pink dots define the tricuspid valve area, white dots indicate the vena cava inferior ostium, dark-yellow dots represent His bundle recording site, light-yellow dot indicates the coronary sinus ostium, brown dot denotes the place of radiofrequency application. Ablation was performed using pulsatile radio-frequency applications, hence the relatively large number of applications. Fig. A left anterior oblique (LAO) view, Fig. B right anterior oblique (RAO) view, Fig. C caudal view 


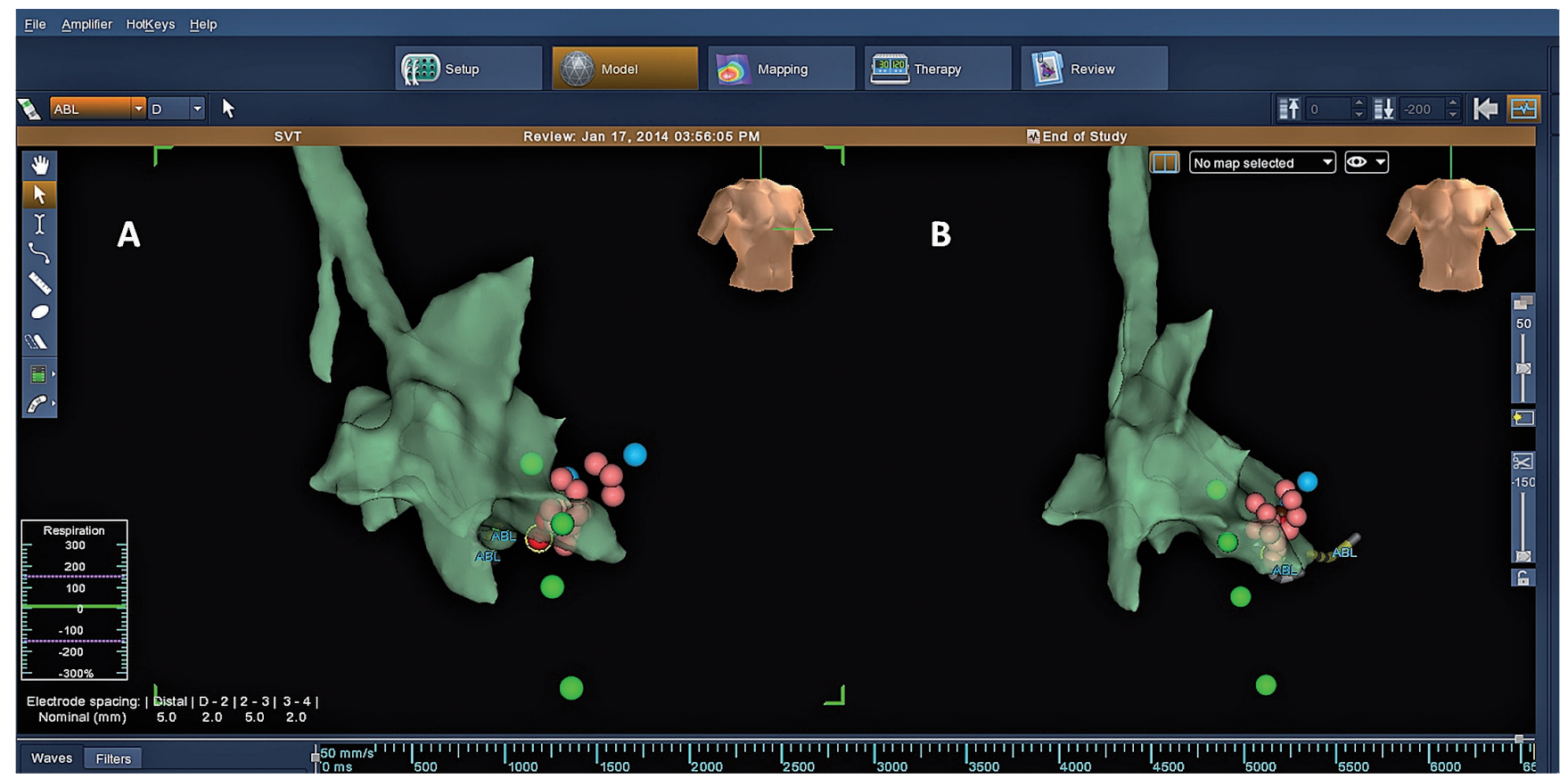

Fig. 2. EnSite NavX mapping during cryoablation of the slow pathway of atrioventricular node in a women at 23 weeks of gestation. Electroanatomical map of the upper part of the right atrium. Blue dots indicate the course of the coronary sinus, pink dots the places of cryomaping, red dot the place of cryoablation. Green dots formed in the initial stage of mapping depicting the location of the electrodes in the vena cava inferior and free wall of the right atrium. Fig. A right anterior oblique (RAO) view, Fig B. anteroposterior (AP) view

\section{Discussion}

The first finding of the study is that an experienced operator using electroanatomical system is usually able to ablate arrhythmia substrate in pregnant women without the use of X-ray fluoroscopy, even for the positioning of the catheters. However, difficulties in obtaining venous access may occur and may become the main reason for procedure failure. In the literature, mostly single cases of ablation during pregnancy are reported ${ }^{5,6}$ and the presented series of cases is one of the most numerous. Therefore, clinical problems faced by surgeons and unique features of these procedures are inadequately described.

In the study group, about $80 \%$ of the arrhythmias were supraventricular tachycardias and $20 \%$ were ventricular arrhythmias of the right ventricular outflow tract. That confirms the view presented in the reports of other researchers that supraventricular tachycardias predominate in this group of patients.$^{6-9}$ Pregnant women with WPW syndrome, AT and PJRT constituted 2/3 of the study group, whereas only a small proportion had AVNRT which prevailed in the control group. These results are also consistent with the results of other researchers. ${ }^{6-9}$ Table 3 shows the available data in literature about the characteristics of arrhythmias treated with ablation in pregnant women. Analysis of these reports leads to the estimation that the most frequent arrhythmia is WPW syndrome. This data obliges us to pay closer attention to the women with cardiac arrhythmias, and particularly to those with WPW syndrome and AT, because of the high risk of the disease worsening its course during pregnancy.

In the study group, most women were diagnosed with arrhythmia before pregnancy. This observation is consistent with the observation that only less than $4 \%$ of women have their first event of arrhythmia during pregnancy. During pregnancy symptoms associated with the occurrence of supraventricular tachycardia get worse in about $29 \%$ of patients. The increased levels of sex hormones may result in both the acceleration of the heart rate and the increase of the cardiac output. ${ }^{17-21}$

The analysis of the subgroup of patients with a history of pregnancies in the past helps to draw attention to two important issues. Firstly, exacerbation of the arrhythmia in prior pregnancy indicates the risk of recurrence in a subsequent pregnancy. Therefore, it is advisable to consider ablation even in the case when the arrhythmia symptoms diminish after birth, especially when WPW syndrome, AT or PJRT are found. Secondly, the absence of arrhythmia symptoms in the prior pregnancy does not guarantee their absence in the subsequent pregnancies.

Although commonly used in patients, femoral access is difficult in pregnant women because of the compression of the inferior vena cava by the uterus and related problems in the positioning of the catheters. In our study group, the difficulties in obtaining vascular access became a direct cause of abandoning the procedure in one patient.

The next result of the study is a confirmation of the feasibility of the two stage approach in performing ablation 
Table 3. Case reports of ablation of cardiac arrhythmias in pregnant women in literature (in one case ablation delayed until post-partum period)

\begin{tabular}{|c|c|c|c|c|}
\hline Author & Arrhythmia & $\begin{array}{l}\text { Number of cases treated } \\
\text { without fluoroscopy }\end{array}$ & $\begin{array}{c}\text { Mother age/age of } \\
\text { pregnancy }\end{array}$ & Fluoroscopy \\
\hline Berruezo et al $2007^{8}$ & $\begin{array}{c}\text { AT } \\
\text { WPW/AF }\end{array}$ & 2 & $\begin{array}{l}30 \text { years } / 30 \mathrm{hbd} \\
20 \text { years } / 10 \mathrm{hbd}\end{array}$ & $\begin{array}{l}481 \mathrm{~s} \\
109 \mathrm{~s}\end{array}$ \\
\hline Bombelli et al. $2003^{9}$ & $\begin{array}{c}\text { AVNRT } \\
\text { WPW } \\
\text { WPW Coumel }\end{array}$ & 3 & $\begin{array}{l}28 \text { years } / 28 \mathrm{hbd} \\
27 \text { years } / 29 \mathrm{hbd} \\
32 \text { years } / 30 \mathrm{hbd}\end{array}$ & $\begin{array}{l}8 \min 36 s \\
6 \min 48 s \\
29 \min 36 s\end{array}$ \\
\hline Bongiorni et al. $2008^{10}$ & AVNRT & 1 & $10 \mathrm{hbd}$ & no \\
\hline Dominguez et al. $1999^{11}$ & WPW & 1 & 32 years $/ 20 \mathrm{hbd}$ & $70 \mathrm{~s}$ \\
\hline Fergusson et al. $2011^{7}$ & AT & 1 & 20 years $/ 27 \mathrm{hbd}$ & no \\
\hline $\begin{array}{l}\text { Forgione et al. } 1994^{12} \text { (ablation } \\
\text { delayed until post-partum period) }\end{array}$ & AT & 1 & $\begin{array}{l}29 \text { years/last week of } \\
\text { pregnancy }\end{array}$ & \\
\hline Kanjwal et al. $2005^{13}$ & WPW/AVRT & 1 & 32 years $/ 22 \mathrm{hbd}$ & $7 \min 37 s$ \\
\hline Manjaly et al $2011^{14}$ & WPW/AF/NF & 1 & 33 years $/ 15 \mathrm{hbd}$ & no \\
\hline Szumowski et al. $2010^{15}$ & $\begin{array}{c}3-\text { PJRT } \\
3-\text { WPW/AF/AVRT } \\
2 \text { - AT } \\
1-\text { AVNRT }\end{array}$ & 3 & $24-34$ years $/ 12-38 \mathrm{hbd}$ & $\begin{array}{c}6 \text { procedures with } X \text {-ray } 42 \pm 37 \\
3 \text { procedures without } X \text {-ray }\end{array}$ \\
\hline Wu et al. $2012^{16}$ & AT & 1 & 32 years $/ 10 \mathrm{hbd}$ & minimal fluoroscopy (55 s) \\
\hline
\end{tabular}

hbd - weeks of pregnancy; EF - ejection fraction; VES - ventricular extrasystole; AT - atrial tachycardia; WPW - Wolf-Parkinson-White syndrome; AF - atrial fibrillation; AVRT - atrioventricular tachycardia, PJRT - permanent junctional reciprocal tachycardia; AVNRT - atrioventricular nodal reentry tachycardia.

in pregnant women. The first stage, limited to the extent necessary to control arrhythmia, may be provided during pregnancy. The complete arrhythmia substrate ablation may be performed after delivery.

According to the presented study, serious cardiac arrhythmias in pregnant women seem to be rare. However, their incidence may be underestimated due to the lack of awareness among obstetricians and cardiologists that such arrhythmias may be treated with ablation. Therefore, it is very important to raise awareness about the possibility of performing ablation procedures without the use of X-rays in pregnant women.

The main limitation of the study was its retrospective and observational character. Missing or incomplete data present another limitation. The prevalence of serious cardiac arrhythmias in the total population of pregnant women is currently unknown because few doctors are aware of the possibility to perform ablation during pregnancy.

\section{Conclusions}

Ablation of arrhythmias in pregnant women constitute about $0.2 \%$ of the total number of ablation procedures. For women of reproductive age this percentage is higher and reaches $1 \%$. An experienced surgeon using an electroanatomical system is usually able to ablate arrhythmia substrate without the use of X-ray fluoroscopy, even for positioning of the catheters. The most prevalent causes of arrhythmias in pregnant women requiring ablation are accessory pathways and ATs. In pregnancy, the procedure tailored to the patient's needs should be performed.

\section{References}

1. European Society of Gynecology (ESG); Association for European Paediatric Cardiology (AEPC); German Society for Gender Medicine (DGesGM), Regitz-Zagrosek V, Blomstrom Lundqvist C., et al. ESC Committee for Practice Guidelines. ESC 2011 Guidelines on the management of cardiovascular diseases during pregnancy: the task force on the management of cardiovascular diseases during pregnancy of the European Society of Cardiology (ESC). Eur Heart J. 2011; 32:3147-3197.

2. Shotan A, Ostrzega E, Mehra A, Johnson JV, Elkayam U. Incidence of arrhythmias in normal pregnancy and relation to palpitations, dizziness, and syncope. Am J Cardiol. 1987; 79:1061-1064.

3. Sommerkamp SK, Gibson A. Cardiovascular disasters in pregnancy. Emerg Med Clin North Am. 2012;30:949-959.

4. Damilakis J, Theocharopoulos N, Perisinakis K, et al. Conceptus radiation dose and risk from cardiac catheter ablation procedures. Circulation. 2001;104:893-897.

5. Clark JM, Bigelow AM, Crane SS, Khoury FR. Catheter ablation of supraventricular tachycardia without fluoroscopy during pregnancy. Obstet Gynecol. 2014;123:Suppl.44S-45S.

6. Stec S, Krynski T, Baran J, Kulakowski P. "Rescue” ablation of electrical storm in arrhythmogenic right ventricular cardiomyopathy in pregnancy. BMC Cardiovasc Disord. 2013;13:58.

7. Ferguson JD, Helms A, Mangrum JM, DiMarco JP. Ablation of incessant left atrial tachycardia without fluoroscopy in a pregnant woman. J Cardiovasc Electrophysiol. 2011; 22:346-349.

8. Berruezo A, Díez GR, Berne P, Esteban M, Mont L, Brugada J. Low exposure radiation with conventional guided radiofrequency catheter ablation in pregnant women. Pacing Clin Electrophysiol. 2007;30:1299-1302.

9. Bombelli F, Lagona F, Salvati A, Catalfamo L, Ferrari AG, Pappone C. Radiofrequency catheter ablation in drug refractory maternal supraventricular tachycardias in advanced pregnancy. Obstet Gynecol. 2003;102:1171-1173.

10. Bongiorni MG, Di Cori A, Soldati E, et al. Radiofrequency catheter ablation of atrioventricular nodal reciprocating tachycardia using intracardiac echocardiography in pregnancy. Europace. 2008;10:1018-1021.

11. Domínguez A, Iturralde P, Hermosillo AG, Colin L, Kershenovich $S$, Garrido LM. Successful radiofrequency ablation of an accessory pathway during pregnancy. Pacing Clin Electrophysiol. 1999;22:131-134. 
12. Forgione FN, Acquati F, Caico SI, Tagliagambe L. Incessant ectopic atrial tachycardia in pregnancy: Radiofrequency catheter ablation in immediate postpartum with disappearance of tachycardia-related dilated cardiomyopathy. G Ital Cardiol. 1994; 24:755-761.

13. Kanjwal Y, Kosinski D, Kanj M, Thomas W, Grubb B. Successful radiofrequency catheter ablation of left lateral accessory pathway using transseptal approach during pregnancy. J Interv Card Electrophysiol. 2005;13:239-242.

14. Manjaly ZR, Sachdev B, Webb T, Rajappan K. Ablation of arrhythmia in pregnancy can be done safely when necessary. Eur J Obstet Gynecol Reprod Biol. 2011;157:116-117.

15. Szumowski L, Szufladowicz E, Orczykowski M, et al. Ablation of severe drug-resistant tachyarrhythmia during pregnancy. $J$ Cardiovasc Electrophysiol. 2010; 21:877-882.
16. Wu H, Ling LH, Lee G, Kistler PM. Successful catheter ablation of incessant atrial tachycardia in pregnancy using three-dimensional electroanatomical mapping with minimal radiation. Intern Med J. 2012:42:709-712.

17. Lee $\mathrm{SH}, \mathrm{Chen} \mathrm{SA}, \mathrm{Wu} \mathrm{TJ}$, et al. Effects of pregnancy on first onset and symptoms of paroxysmal supraventricular tachycardia. Am J Cardiol. 1995;76: 675-678.

18. Gleicher N, Meller J, Sandler R, Sullum S. Wolff-Parkinson-White Syndrome in pregnancy. Obst Gynecol. 1981;58:748-752.

19. Hubbard W, Jenkins B, Ward D. Persistent atrial tachycardia in pregnancy. Br Med J. 1983;287:327.

20. Widerhorn J, Widerhorn A, Rahimtoola S, Elkayam U. WPW syndrome during pregnancy: increased incidence of supraventricular arrhythmias. Am Heart J. 1992; 123:769-798.

21. Tawam M, Levine J, Mendelson M, Goldberger J, Dyer A, Kadish A. Effect of pregnancy on paroxysmal supraventricular tachycardia. Am J Cardiol. 1993;72: 838-840. 